\title{
Endometrial Preparation for Frozen Embryo Transfer by Supplemented Natural Cycle versus Hormone Replacement Cycle in Regularly Cycling Women
}

\section{Suzan Samir Elsharkawy ${ }^{1 *}$, Tamer Hanafy Mahmoud ${ }^{1}$, Mervat Sheikh-Elarab Elsedeek1, Eman Monier Abd Elkader Amer ${ }^{2}$}

${ }^{1}$ Faculty of Medicine, University of Alexandria, Alexandria, Egypt

${ }^{2}$ Ministry of Health Hospitals, Alexandria, Egypt

Email: *s_abdelrahim00@alexmed.edu.eg

How to cite this paper: Elsharkawy, S.S., Mahmoud, T.H., Elsedeek, M.S.-E. and Amer, E.M.A.E. (2019) Endometrial Preparation for Frozen Embryo Transfer by Supplemented Natural Cycle versus Hormone Replacement Cycle in Regularly Cycling Women. Open Journal of Obstetrics and Gynecology, 9, 827-837. https://doi.org/10.4236/ojog.2019.96081

Received: April 23, 2019

Accepted: June 9, 2019

Published: June 12, 2019

Copyright $\odot 2019$ by author(s) and Scientific Research Publishing Inc. This work is licensed under the Creative Commons Attribution International License (CC BY 4.0).

http://creativecommons.org/licenses/by/4.0/

\begin{abstract}
BACKGROUND: The first successful pregnancy from a frozen-thawed embryo transfer (FTET) was reported in 1983 and after more than three decades, significant changes have been introduced into clinical practice. OBJECTIVE: To compare endometrial preparation for frozen thawed embryo transfer (FTET) in supplemented natural cycle (NC) by hCG (human chorionic gonadotropin) versus HRT (hormonal replacement therapy) by estrogen and progesterone in regularly cycling women. METHODS: A prospective trial was conducted on 40 patients that were divided into two treatment groups. The first group underwent endometrial preparation by supplemented natural cycle by HCG, and the second group underwent endometrial preparation by HRT (estrogen and progesterone). RESULTS: No significant difference was revealed between the two groups regarding ongoing clinical pregnancy rate. CONCLUSION: This study concluded that there is no significant difference in clinical pregnancy rate between the two methods of endometrial preparation for frozen thawed embryo transfer; supplemented natural cycle by hCG or HRT by estrogen and progesterone, in regularly cycling women.
\end{abstract}

\section{Keywords}

Intracytoplasmic Sperm Injection (ICSI), Infertility, Frozen Cycles

\section{Introduction}

The first successful pregnancy from a frozen-thawed embryo transfer (FTET) 
was reported in 1983 [1] and after more than three decades, significant changes have been introduced into clinical practice. Improvements in cryopreservation techniques have helped to improve the efficiency of in-vitro fertilization (IVF) [2] [3] [4]. These great modifications caused vitrification to be introduced as the main cryopreservation method in almost every laboratory all over the world. Vitrification was first described by Kuwayama et al. [5].

Intra Cytoplasmatic Sperm Injection (ICSI) treatment cycles often produce more embryos than can be transferred during the concomitant fresh treatment cycle. Additionally, in some patients embryo transfer is postponed for medical reasons (e.g. ovarian hyperstimulation syndrome). Cryopreservation of these embryos provides both physicians and patients safe, successful and presumably cost-efficient trials [6] [7]. Recent implementation of single embryo transfer strategies in ICSI programs has increased the need for successful frozen thawed embryo transfer (FTET) programs. To get a successful FTET program, it is critical to synchronize the endometrial development with the embryo [8] [9]. To achieve this, FTET requires extensive preparation, timing and planning. Several methods for endometrium preparation have been developed recently, vide infra.

Embryos may be stored soon after fertilization at the pronuclear stage, which is relatively stable with high survival rates (70\%) after freezing and pregnancy rates of $17 \%-31 \%$ [10]. Most embryos are being frozen at the cleavage stage following the transfer of fresh embryos 2 or 3 days after oocyte retrieval. Blastocyst culture allows identification and selection of a single embryo for transfer into the uterus to reduce the risk of multiple pregnancies. Pregnancy rates are around $60 \%$ per transfer of thawed vitrified blastocysts [10].

Multiple factors affect the success of frozen embryo transfer cycle, like patient's age, embryo quality before freezing, the number of embryos transferred freezing and thawing protocol, and endometrial preparation [11].

Embryo implantation is the most important step of assisted reproductive techniques (ART) and it is determined by three main parameters: embryo quality, endometrial receptivity and optimal synchronization between endometrial growth and embryonic development [11].

Endometrial receptivity, is the state of the endometrium during the window of implantation (WOI), which starts 4 - 5 days after the endogenous/exogenous progesterone stimulation and ends 9 - 10 days afterward [12]. At that time, the endometrium acquires new adhesive potentials allowing embryo adhesion and invasion [13] [14]. No effective diagnostic tools are yet available to precisely predict endometrial receptivity [15].

Frozen thawed embryo transfer (FTET) must be synchronized so that the age of the embryos after thawing corresponds to the age of the endometrium on the day of embryo transfer [16]. Endometrium preparation before FTET can be carried out through different cycle regimens. They consist of a purely natural cycle (NC) with LH (luteinizing hormone) measuring in blood or urine, or a natural modified cycle (NMC) in which hCG is given to the patients to schedule embryo transfer instead of measuring luteinizing hormone (LH), or an artificial cycle 
with estradiol (E2) and progesterone (P4), with or without using gonadotropin-releasing hormone $(\mathrm{GnRH})$ analogs and lastly, stimulated cycles with low doses of gonadotropins [17].

Most authors recommended a minimum endometrial thickness of $7-8 \mathrm{~mm}$ at the time of ovulation or initiation of progesterone therapy before frozen-thawed embryo transfer [18] [19]. However, many studies have proved better results when endometrial thickness was between $9-14 \mathrm{~mm}$ [20] [21], however there is no firm evidence to support cancellation when the endometrium is thinner [22].

\section{Aim of the Work}

The aim of the present study was to compare endometrial preparation for frozen-thawed embryo transfer (FTET) by supplemented natural cycle versus hormone replacement cycle by estrogen and progesterone in regularly menstruating women.

\section{Materials}

This study was a prospective cohort study. It was conducted in the period between April to November 2018. Sample size calculation was done using Creative Research Systems that offers a free sample size calculator online (http://www.surveysystem.com/sscalc.htm) which was based on last Egyptian census in 2014, which gave us 40 cases as an adequate sample.

A total of 57 Patients were recruited into this study, from to El-Shat by Maternity University Hospital out patient's infertility clinic. 17 dropped out, mainly because they did not show up for ET after starting endometrial preparation. So recruitment continued till 40 patients were randomized (by closed envelop system) with 20 cases in each study group. They were categorized as follows:

1) Group I: cases underwent endometrial preparation by supplemented natural cycle by HCG.

2) Group II: cases underwent endometrial preparation by HRT (estrogen and progesterone).

\section{Inclusion criteria:}

1) Age between 20 - 40 years.

2) Have frozen embryos and undergoing preparation for transfer.

3) ICSI cycle in which embryos were frozen done since $<1$ year.

4) Regular ovulatory menstrual cycles.

5) Embryos frozen on day 3.

\section{Exclusion criteria:}

1) Previous uterine surgery.

2) Evidence of endometrial, uterine or pelvic pathology.

3) Medical disorders or regular intake of medications.

4) Recurrent implantation failure cases.

\section{Methods}

The study was explained to women included, patient questions were answered 
and written informed consent was obtained from them.

The cases were randomly allocated to two groups (I and II) each of them consisted of 20 patients.

Eligible and consenting cases were subjected to:

1) History of Infertility (primary or secondary), duration of infertility, number of previous ICSI trials, oocyte retrieved and embryos fertilized.

2) Examination and BMI (body mass index) calculation.

3) Trans-vaginal ultrasound (TVUS): On day $1-3$ to exclude endometrial abnormality or functional ovarian cyst.

4) Treatment protocol:

\section{a) Endometrial preparation}

Group I: cases were instructed to come for evaluation starting from day 5 of the cycle by regular us follicular scanning every 3 days till the leading follicle reached $18 \mathrm{~mm}$ and endometrium was seen as triple line and $\geq 8 \mathrm{~mm}$ then 5000 iu HCG were administrated. Luteal support with progesterone $400 \mathrm{mg}$ vaginal suppositories once daily (prontogest $400^{\circledR}$, Actavis, Devon, UK) started $48 \mathrm{~h}$ after HCG. And if pregnancy test positive, continued till 12 weeks of pregnancy.

Group II: Endometrial preparation began from third day of menstruation by estradiolvalerate $6 \mathrm{mg} /$ day (cycloprogenova ${ }^{\circledR}$, Bayer, Germany) till endometrial thickness exceeded $8 \mathrm{~mm}$ by transvaginal us then progesterone $400 \mathrm{mg}$ vaginal suppositories twice daily were added (prontogest 400, Actavis, Devon, UK). And if pregnancy test positive, continued till 12 weeks of pregnancy and estrogen continued till 7 weeks of pregnancy.

\section{b) Embryo transfer (ET)}

Embryo transfer was done in the fourth day of progesterone administration. Cancellation of Embryo transfer in group I was done if follicle failed to reach size $18 \mathrm{~mm}$ or endometrium thickness was less than $8 \mathrm{~mm}$ or triple line. While in group II cases failed to reach endometrial thickness $8 \mathrm{~mm}$ or a triple line were cancelled.

c) Evaluation of cycle outcome

i) BHCG (beta subunit) testing done 14 days after embryo transfer to diagnose chemical pregnancy rate.

ii) Transvaginal us done 2 weeks after testing BHCG to diagnose clinical pregnancy rate.

\section{Main outcome measures:}

i) Chemical pregnancy rate: positive pregnancy test 2 weeks after ET.

ii) Implantation rate: number of embryos transferred/number of gestational sacs seen by TVUS.

iii) On-going pregnancy rate: pregnancy continuing after detection of fetal cardiac pulsation.

iv) Miscarriage rate.

\section{Secondary outcome measures}

Endometrial thickness measuring; at HCG administration day in group I, and before adding progesterone in group II. 


\section{Statistical analysis of the data}

Data were fed to the computer and analyzed using IBM SPSS software package version 22. Quantitative data were described using mean and standard deviation error of mean. Comparison between the different studied groups was analyzed using independent T-test. Significance of the obtained results was judged at the $5 \%$ level.

\section{Results}

The study was designed as a prospective randomized clinical trial, it was conducted on 40 patients were divided into two treatment groups; the first group underwent endometrial preparation by supplemented natural cycle by HCG. On the other hand the second group underwent endometrial preparation by estrogen and progesterone. The main limitation of this study was the dropped cases which we overcome by increasing recruitment number and time.

Table 1 shows the comparison between the two studied groups regarding demographic data, regarding age the mean age group in group I was $31.35 \pm$ 3.70 , while in group II was $28.50 \pm 5.28$ and regarding BMI in group 1 was 31.80 \pm 2.21 and that of group II was $31.40 \pm 3.05$. On comparing the two groups it was found that there was no significant difference between the two groups regarding age and BMI.

Regarding gravidity and the parity it was found that the mean number of gravidity was $0.55 \pm 0.69$ and $0.50 \pm 0.69$ in group I and group II respectively while the mean number of parity in group I was $0.25 \pm 0.44$ and that of group II was $0.25 \pm 0.44$. On comparing the two groups it was found that there was no significant difference between the two groups regarding type of infertility.

The duration of infertility the mean duration in group I was $5.15 \pm 1.60$ and that of group II was $5.50 \pm 2.76$, with no statistical significant difference between the two groups.

According to endometrial thickness (ET) at time of embryo transfer, the mean endometrial thickness in group I was $10.95 \pm 1.57$ and that of group II was $9.0 \pm$

Table 1. Comparison between the studied groups according to demographic data.

\begin{tabular}{ccccc}
\hline & $\begin{array}{c}\text { Group I } \\
(\mathbf{n}=20)\end{array}$ & $\begin{array}{c}\text { Group II } \\
(\mathbf{n}=20)\end{array}$ & Test of Sig. & P \\
\hline $\begin{array}{c}\text { Age (years) } \\
\text { Mean } \pm \text { SD } \\
\text { BMI } \\
\text { Mean } \pm \text { SD } \\
\text { Gravidity } \\
\text { Mean } \pm \text { SD } \\
\text { Parity }\end{array}$ & $31.35 \pm 3.70$ & $28.50 \pm 5.28$ & $\mathrm{~T}=1.977$ & 0.055 \\
$\begin{array}{c}\text { Mean } \pm \text { SD } \\
\text { of infertility (years) } \\
\text { Mean } \pm \text { SD }\end{array}$ & $0.55 \pm 0.69$ & $0.50 \pm 0.69$ & $\mathrm{U}=191.000$ & 0.782 \\
\hline
\end{tabular}

t: Student t-test; U: Mann Whitney test; p: p value for comparing between the two groups. 
1.62. On comparing the two groups there was statistical significant difference between the two groups regarding ET in favor of group I ( $p=0.001)$. The interval from cycle day 1 to embryo transfer; in group I the mean interval was $12.75 \pm$ 1.12 and that of group II was $10.95 \pm 2.54$. On comparing the two groups there was statistical significant difference between the two groups $(p=0.006)$ as shown in Table 2 .

Regarding total implantation rate; the mean rate in group I was $0.35 \pm 0.29$ and that of group II was $0.17 \pm 0.22$. On comparing the two groups there was statistical significant difference between the two groups regarding total implantation rate $(\mathrm{p}=0.039)$ as shown in Table 2.

The cancellation rate was $0.0 \%$ in group I while in group II was $10 \%$. The clinical pregnancy rate was $65 \%$ in group I while in group II was $45 \%$. The miscarriage rate in group I was $25 \%$ while in group II was $5 \%$. The live birth rate was $40 \%$ in the two groups with no statistical significant difference between the two groups as shown in Table 3.

\section{Discussion}

The transfer of frozen-thawed embryos has important implications for the management of women undergoing ovarian stimulation for IVF (in vitro fertilization). By providing the possibility of a further embryo transfer, this strategy

Table 2. Comparison between the studied groups according to cycle variables and Total implantation rate.

\begin{tabular}{ccccc}
\hline & $\begin{array}{c}\text { Group I } \\
(\mathbf{n}=20)\end{array}$ & $\begin{array}{c}\text { Group II } \\
(\mathbf{n}=20)\end{array}$ & Test of Sig. & P \\
\hline $\begin{array}{c}\text { Endometrium thickness at time of } \\
\text { ET (embryo transfer) } \\
\text { Mean } \pm \text { SD }\end{array}$ & $10.95 \pm 1.57$ & $9.0 \pm 1.62$ & $\mathrm{t}=3.861^{*}$ & $<0.001^{*}$ \\
$\quad \begin{array}{c}\text { Interval from cycle D1 to ET } \\
\text { (embryo transfer) } \\
\quad \text { Mean } \pm \text { SD. }\end{array}$ & $12.75 \pm 1.12$ & $10.95 \pm 2.54$ & $\mathrm{t}=2.900^{*}$ & $0.006^{*}$ \\
$\begin{array}{c}\text { Total implantation rate Mean } \pm \text { SD } \\
\quad 0.35 \pm 0.29\end{array}$ & $0.17 \pm 0.22$ & $\mathrm{U}=128.500^{*}$ & $0.039^{*}$ \\
\hline
\end{tabular}

U: Mann Whitney test; t: Student t-test; p: $p$ value for comparing between the two groups; ${ }^{*}$ : Statistically significant at $\mathrm{p} \leq 0.05$.

Table 3. Comparison between the studied groups according to cycle outcomes.

\begin{tabular}{|c|c|c|c|c|c|c|}
\hline & \multicolumn{2}{|c|}{$\begin{array}{l}\text { Group I } \\
(n=20)\end{array}$} & \multicolumn{2}{|c|}{$\begin{array}{l}\text { Group II } \\
(n=20)\end{array}$} & \multirow{2}{*}{$\square^{\square}$} & \multirow{2}{*}{$\mathrm{p}$} \\
\hline & No. & $\%$ & No. & $\%$ & & \\
\hline Cancellation rate & 0 & 0.0 & 2 & 10.0 & 2.105 & ${ }^{\mathrm{FE}} \mathrm{p}=0.487$ \\
\hline Clinical pregnancy & 13 & 65.0 & 9 & 45.0 & 1.616 & 0.204 \\
\hline Miscarriage rate & 5 & 25.0 & 1 & 5.0 & 3.137 & ${ }^{\mathrm{FE}} \mathrm{p}=0.182$ \\
\hline Live birth rate & 8 & 40.0 & 8 & 40.0 & 0.0 & 1.000 \\
\hline
\end{tabular}

$\chi^{2}$ : Chi square test; FE: Fisher Exact; p: $p$ value for comparing between the two groups. 
increases the cumulative pregnancy rate and reduces cost. While the implantation rate of frozen-thawed embryos is lower than that obtained with fresh embryo transfer, this may reflect the protocols used to select the embryos for the fresh transfer rather than the adverse effect of freezing. Various attempts have been made to improve the success of FTET [23], since Trounson and Mohr reported the first successful pregnancy in 1983.

The current study was conducted to compare 2 different protocols for endometrial preparation in FTET cycles in regularly cycling women. It was conducted in 40 infertile women underwent cryo embryo transfer as treatment for infertility, Group I (20 cases) underwent endometrial preparation by supplemented natural cycle by HCG and progesterone as aluteal support and Group II (20 cases) underwent sequential endometrial preparation by HRT by estrogen and progesterone, There was no statistical significant difference between the two studied groups regarding age, BMI, gravidity, parity, duration of infertility and type of infertility.

The study demonstrated that, the interval from cycle day 1 to embryo transfer was significantly higher in group I and this slower endometrium development might be more physiological. Also, there was significant difference between the studied groups regarding endometrial thickness. It was significantly higher in group I as the mean thickness was $10.95 \pm 1.57$ and that of group II was $9.0 \pm$ 1.62. Also, there was significant difference between both groups regarding total implantation rate, it was higher in group I as the mean value was $0.35 \pm 0.29$ compared with group II as the mean value was $0.17 \pm 0.22(\mathrm{p}+0.03)$ and this finding however, cannot be confidently stated since the number of embryos transferred was significantly higher in group II.

In our study, it was noted that when analyzing cycle outcomes, the cancellation rate was higher in group II $10 \%$ comparable to group I which was $0 \%$ as there was 2 cases cancelled because of not reaching endometrial thickness $8 \mathrm{~mm}$ or a triple line. The clinical pregnancy rate in group I was $65 \%$ and that in group II was $45 \%$ with no statistical significant difference between the two groups.

The miscarriage rate in group 1 was $25 \%$ which was higher than group II that was $5 \%$. Also the live birth rate showed no statistical significant difference as the live birth rate in both groups was $40 \%$.

Our findings are similar to results from a previous Cochrane review (Ghobara $\mathrm{T}$ et al., 2008) [24] which included seven randomized controlled trials and included 100 patients, they concluded that no single method for FTET was proved to be more effective than the other as regard the clinical pregnancy rate per woman.

In addition, a 2017 update of the 2008 Cochrane review also showed no evidence of a difference between the two cycles in rates of live birth or miscarriage rates [25].

In a retrospective study of more than 4000 cycles, which was also included in the review by Groenewoud et al. (2013) [26] the NC was compared with the substituted cycle (estradiol and progesterone). The authors found a higher posi- 
tive pregnancy test rate in the last-mentioned group, but reported comparable clinical pregnancy and delivery rates in the two protocols.

Queenan JT et al. (1994) [27] showed similar results with programmed and natural cycle in patients with frozen-thawed embryos. However, Xiao et al. (2012) [28] showed that natural cycle had a higher trend of clinical pregnancy rate for FTET in their study. Also Chang et al. (2011) [29] showed that using natural cycles with or without hCG had better outcomes compared with hormonally manipulated cycles.

On the other hand, some authors supported artificial cycle frozen-thawed embryo transfer (AC-FTET) as it can be more easily scheduled, which leads to a better control of embryo thawing and transfer, better timing and also decreases cancellation rates compared with natural cycle frozen-thawed embryo transfer (NC-FTET). This is the result of ovulation suppression and the programmed replacement of exogenous hormones [30] [31] [32] [33].

However, these advantages are somewhat counterbalanced by its possible adverse effects through exposure to exogenous hormones, higher risk of thrombo-embolic events, and providing a higher financial burden on patients.

Although NC-FTET is more complicated to plan due to its requirement for more frequent ultrasonographic evaluations of the dominant follicle, the risk of unexpected ovulation and insufficient development of the endometrium, its advantages such as being more patient friendly, convenience, less medication, and lower price cannot be denied.

\section{Conclusion}

This study concluded that there is no significant difference in clinical pregnancy rate between the two methods of endometrial preparation for frozen thawed embryo transfer; supplemented natural cycle by hCG or HRT by estrogen and progesterone, in regularly cycling women.

\section{Conflicts of Interest}

The authors declare no conflicts of interest regarding the publication of this paper.

\section{References}

[1] Trounson, A. and Mohr, L. (1983) Human Pregnancy Following Cryopreservation, Thawing and Transfer of an Eight-Cell Embryo. Nature, 305, 707-709. https://doi.org/10.1038/305707a0

[2] Kolibianakis, E.M., Venetis, C.A. and Tarlatzis, B.C. (2009) Cryopreservation of Human Embryos by Vitrification or Slow Freezing: Which One Is Better? Current Opinion in Obstetrics and Gynecology, 21, 270-274. https://doi.org/10.1097/GCO.0b013e3283297dd6

[3] Stehlik, E., Stehlik, J., Katayama, K.P., Kuwayama, M., Jambor, V., Brohammer, R., et al. (2005) Vitrification Demonstrates Significant Improvement versus Slow Freezing of Human Blastocysts. Reproductive BioMedicine Online, 11, 53-57. 
https://doi.org/10.1016/S1472-6483(10)61298-9

[4] Liebermann, J., Dietl, J., Vanderzwalmen, P. and Tucker, M.J. (2003) Recent Developments in Human Oocyte, Embryo and Blastocyst Vitrification: Where Are We Now? Reproductive BioMedicine Online, 7, 623-633. https://doi.org/10.1016/S1472-6483(10)62084-6

[5] Kuwayama, M., Vajta, G., Kato, O. and Leibo, S.P. (2005) Highly Efficient Vitrification Method for Cryopreservation of Human Oocytes. Reproductive BioMedicine Online, 11, 300-308. https://doi.org/10.1016/S1472-6483(10)60837-1

[6] Aflatoonian, A., Mansoori, M.F., Mashayekhy, M. and Mohamadian, F. (2010) Comparison of Early Pregnancy and Neonatal Outcomes after Frozen and Fresh Embryo Transfer in ART Cycles. Journal of Assisted Reproduction and Genetics, 27, 695-700. https://doi.org/10.1007/s10815-010-9470-z

[7] Belva, F., Henriet, S., Van den Abbeel, E., Camus, M., Devroey, P., Van der Elst, J., et al. (2008) Neonatal Outcome of 937 Children Born after Transfer of Cryopreserved Embryos Obtained by ICSI and IVF and Comparison with Outcome Data of Fresh ICSI and IVF Cycles. Human Reproduction, 23, 2227-2238.

https://doi.org/10.1093/humrep/den254

[8] Edwards, R.G. (1988) Human Uterine Endocrinology and the Implantation Window. Annals of the New York Academy of Sciences, 541, 445-454.

https://doi.org/10.1111/j.1749-6632.1988.tb22281.x

[9] Harper, M.J. (1992) The Implantation Window. Baillière's Clinical Obstetrics and Gynaecology, 6, 351-371. https://doi.org/10.1016/S0950-3552(05)80092-6

[10] Tucker, M.J., Cohen, J. and Massey, J.B. (1991) Partial Dissection of the Zona Pellucid of Frozen-Thawed Human Embryos May Enhance Blastocyst Hatching, Implantation, and Pregnancy Rates. American Journal of Obstetrics \& Gynecology, 165, 341-344. https://doi.org/10.1016/0002-9378(91)90088-9

[11] Behr, B. and Shu, Y. (2010) Cryopreservation of Pronuclear Stage Human Embryos. In: Chian, R. and Quinn, P., Eds., Fertility Cryopreservation, Cambridge University Press, Cambridge, 76-88.

[12] Rashid, N.A., Lalitkumar, S., Lalitkumar, P.G. and Gemzell-Danielsson, K. (2011) Endometrial Receptivity and Human Embryo Implantation. American Journal of Reproductive Immunology, 66, 23-30. https://doi.org/10.1111/j.1600-0897.2011.01048.x

[13] Achache, H. and Revel, A. (2006) Endometrial Receptivity Markers, the Journey to Successful Embryo Implantation. Human Reproduction, 12, 731-746. https://doi.org/10.1093/humupd/dml004

[14] Herrler, A., von Rango, U. and Beier, H.M. (2003) Embryo-Maternal Signalling: How the Embryo Starts Talking to Its Mother to Accomplish Implantation. Reproductive BioMedicine Online, 6, 244-256. https://doi.org/10.1016/S1472-6483(10)61717-8

[15] Altmäe, S., Esteban, F.J., Stavreus-Evers, A., Simón, C., Giudice, L., Lessey, B.A., et al. (2014) Guidelines for the Design, Analysis and Interpretation of "OMICS" Data: Focus on Human Endometrium: An Implantation Window. Human Reproduction Update, 20, 12-28. https://doi.org/10.1093/humupd/dmt048

[16] Ming, L., Liu, P., Qiao, J., Lian, Y., Zheng, X., Ren, X., et al. (2012) Synchronization between Embryo Development and Endometrium Is a Contributing Factor for Rescue ICSI Outcome. Reproductive BioMedicine Online, 24, 527-531. https://doi.org/10.1016/j.rbmo.2012.02.001

[17] Wright, K.P., Guibert, J., Weitzen, S., Davy, C., Fauque, P. and Olivennes, F. (2006) 
Artificial versus Stimulated Cycles for Endometrial Preparation Prior to Frozen-Thawed Embryo Transfer. Reproductive BioMedicine Online, 13, 321-325. https://doi.org/10.1016/S1472-6483(10)61434-4

[18] Eftekhar, M., Rahsepar, M. and Rahmani, E. (2013) Effect of Progesterone Supplementation on Natural Frozen-Thawed Embryo Transfer Cycles: A Randomized Controlled Trial. International Journal of Fertility and Sterility, 7, 13-20.

[19] Gelbaya, T.A., Nardo, L.G., Hunter, H.R., Fitzgerald, C.T., Horne, G. and Pease, E.E. (2006) Cryopreserved-Thawed Embryo Transfer in Natural or Down-Regulated Hormonally Controlled Cycles: A Retrospective Study. Fertility and Sterility, 85, 603-609. https://doi.org/10.1016/j.fertnstert.2005.09.015

[20] El-Toukhy, T., Coomarasamy, A., Khairy, M., Sunkara, K., Seed, P. and Khalaf, Y. (2008) The Relationship between Endometrial Thickness and Outcome of Medicated Frozen Embryo Replacement Cycles. Fertility and Sterility, 89, 832-839. https://doi.org/10.1016/j.fertnstert.2007.04.031

[21] Quintero, R.B., Sharara, F.L. and Milki, A.A. (2004) Successful Pregnancies in the Setting of Exaggerated Endometrial Thickness. Fertility and Sterility, 82, 215-217. https://doi.org/10.1016/j.fertnstert.2004.02.099

[22] Ng, E.H., Chan, C.C., Tang, O.S., Yeung, W.S. and Ho, P.C. (2006) The Role of Endometrial and Subendometrial Vascularity Measured by Three Dimensional Power Doppler Ultrasound in the Prediction of Pregnancy during Frozen-Thawed Embryo Transfer Cycles. Human Reproduction, 21, 1612-1617. https://doi.org/10.1093/humrep/dei502

[23] Al-Shawaf, T., Yang, D., Al-Magid, Y., Seaton, A., Iketubosin, F. and Craft, I. (1993) Ultrasonic Monitoring during Replacement of Frozen-Thawed Embryos in Natural and Hormone Replacement Cycles. Human Reproduction, 8, 2068-2074. https://doi.org/10.1093/oxfordjournals.humrep.a137983

[24] Ghobara, T. and Vandekerckhove, P. (2008) Cycle Regimens for Frozen-Thawed Embryo Transfer. Cochrane Database of Systematic Reviews, No. 1, CD003414. https://doi.org/10.1002/14651858.CD003414.pub2

[25] Ghobara, T., Gelbaya, T.A. and Ayeleke, R.O. (2017) Cycle Regimens for Frozen-Thawed Embryo Transfer. Cochrane Database of Systematic Reviews, 7, CD003414. https://doi.org/10.1002/14651858.CD003414.pub3

[26] Groenewoud, E.R., Cantineau, A.E., Kollen, B.J., Macklon, N.S. and Cohlen, B.J. (2013) What Is the Optimal Means of Preparing the Endometrium in Frozen-Thawed Embryo Transfer Cycles? A Systematic Review and Meta-Analysis. Human Reproduction Update, 19, 458-470. https://doi.org/10.1093/humupd/dmt030

[27] Queenan, J.T., Veeck, L.L., Seltman, H.J. and Muasher, S.J. (1994) Transfer of Cryopreserved-Thawed Pre-Embryos in a Natural Cycle or a Programmed Cycle with Exogenous Hormonal Replacement Yields Similar Pregnancy Results. Fertility and Sterility, 62, 545-550. https://doi.org/10.1016/S0015-0282(16)56943-X

[28] Xiao, Z., Zhou, X., Xu, W., Yang, J. and Xie, Q. (2012) Natural Cycle Is Superior to Hormone Replacement Therapy Cycle for Vitrificated-Preserved Frozen-Thawed Embryo Transfer. Systems Biology in Reproductive Medicine, 58, 107-112. https://doi.org/10.3109/19396368.2011.646047

[29] Chang, E.M., Han, J.E., Kim, Y.S., Lyu, S.W., Lee, W.S. and Yoon, T.K. (2011) Use of the Natural Cycle and Vitrification Thawed Blastocyst Transfer Results in Better In-Vitro Fertilization Outcomes. Journal of Assisted Reproduction and Genetics, 28, 369-374. https://doi.org/10.1007/s10815-010-9530-4 
[30] MedOrvieto, R., Feldman, N., Lantsberg, D., Manela, D., Zilberberg, E. and Haas, J. (2016) Natural Cycle Frozen-Thawed Embryo Transfer-Can We Improve Cycle Outcome? Journal of Assisted Reproduction and Genetics, 33, 611-615. https://doi.org/10.1007/s10815-016-0685-5

[31] Peeraer, K., Couck, I., Debrock, S., De Neubourg, D., De Loecker, P., Tomassetti, C., et al. (2015) Frozen-Thawed Embryo Transfer in a Natural or Mildly Hormonally Stimulated Cycle in Women with Regular Ovulatory Cycles: A RCT. Human Reproduction, 30, 2552-2562. https://doi.org/10.1093/humrep/dev224

[32] Groenewoud, E., Cohlen, B., Al-Oraiby, A., Brinkhuis, E.A., Broekmans, F.J., de Bruin, J.P., et al. (2016) A Randomized Controlled, Non-Inferiority Trial of Modified Natural versus Artificial Cycle for Cryo-Thawed Embryo Transfer. Human Reproduction, 31, 1483-1492. https://doi.org/10.1093/humrep/dew120

[33] Le, Q.V., Abhari, S., Abuzeid, O.M., DeAnna, J., Satti, M.A., Abozaid, T., et al. (2017) Modified Natural Cycle for Embryo Transfer Using Frozen-Thawed Blastocysts: A Satisfactory Option. European Journal of Obstetrics \& Gynecology and Reproductive Biology, 213, 58-63. https://doi.org/10.1016/j.ejogrb.2017.04.010 